\title{
Aerobic one-step oxidation of benzene to phenol on copper exchanged HZSM5 zeolites: a mechanistic study
}

\author{
Andreas Tabler, ${ }^{1}$ Anette Häusser ${ }^{1}$ and Emil Roduner ${ }^{1,2 *}$ \\ ${ }^{1}$ Institute of Physical Chemistry, University of Stuttgart, \\ Pfaffenwaldring 55, D-70569 Stuttgart, Germany \\ ${ }^{2}$ Chemistry Department, University of Pretoria, Pretoria 0002, Republic of South Africa
}

\begin{abstract}
*Corresponding author: Prof. Dr. Emil Roduner
Institute of Physical Chemistry

University of Stuttgart

Pfaffenwaldring 55

D- 70569 Stuttgart / Germany

Phone: +49 71168564490

Fax: $\quad+4971168564495$

Email: e.roduner@ipc.uni-stuttgart.de

(preferred way of correspondence)
\end{abstract}

\begin{abstract}
Various $\mathrm{Cu} / \mathrm{HZSM}$ 5-zeolites were prepared and their catalytic properties were investigated by product analysis via GC/MS chromatography in order to trace down the mechanism of the gas phase one-step oxidation of benzene to phenol with molecular oxygen. Comparison of $\mathrm{Cu}$ free and $\mathrm{Cu}$ containing zeolites showed that the activation of $\mathrm{O}_{2}$ takes place at copper centers of the zeolite and high copper loadings lead to high yields of deep oxidation products $\left(\mathrm{CO}, \mathrm{CO}_{2}\right)$. No phenol was formed in the absence of Brønsted acid sites, i.e. on Cu/KZSM5, revealing the bifunctionality of the $\mathrm{Cu} / \mathrm{HZSM} 5$ zeolite. The yields of the various oxidation products and thus the selectivity towards phenol can be influenced by variation of the relative $\mathrm{O}_{2}$ concentration in the reaction mixture, indicating the possibility of a stoichiometric use of $\mathrm{O}_{2}$. The role of the superoxide radical ion $\mathrm{O}_{2}{ }^{\bullet-}$ as a reactive intermediate is discussed and a radical ionic reaction mechanism is suggested.
\end{abstract}

Keywords: benzene oxidation; copper zeolite; bifunctional catalyst; oxygen activation

\section{Introduction}

Phenol has obtained an important role in the chemical industry as a precursor for chemicals like aniline, picric acid or salicylic acid. Nowadays, $90 \%$ of the worldwide production of eight million tons per year is synthesized by the cumene process. The major advantage of this process consists in the two cheap reagents (benzene and propylene) to form the two more expensive products acetone and phenol. Unfortunately the economic efficiency of the cumene process is highly dominated by the acetone price. Furthermore, the necessity of aluminium chloride and phosphoric acid is a main disadvantage from an ecological point of view. These are the reasons why an alternative one-step process for the production of phenol would be desirable. 
Over the last years, copper impregnated zeolites showed their potential as catalysts in the one-step formation of phenol in aqueous solution as well as in the gas phase reaction. Kitamura et al. investigated the benzene oxidation to phenol in aqueous solutions on several copper impregnated zeolites [1]. In this study the HY-zeolite showed the highest catalytic activity for the benzene conversion with a reported selectivity towards phenol of $100 \%$ but with a phenol yield of only $2.5 \%$. Beside the addition of ascorbic acid as a reducing agent, the product extraction and the Cu leaching from the zeolite during the reaction seemed to be some major disadvantages of the liquid-phase reaction.

In the gas-phase reaction, which facilitates the product extraction, the $\mathrm{Cu} / \mathrm{HZSM} 5$-zeolite showed promising results for the phenol formation. Hamada et al. explored the gas-phase reaction on several $\mathrm{Cu} / \mathrm{HZM} 5$-zeolites under different reaction conditions and reported a phenol yield up to $5 \%$ with a selectivity of nearly $30 \%$ [2-4]. Meanwhile phenol yields up to $10 \%$ have been reported [5], but the detailed reaction mechanism for the phenol formation is still unknown. Knowledge of the reaction mechanism would allow the modification of the catalysts and to increase the phenol yields. To clarify the reaction mechanism, Ene et al. investigated the adsorption complexes of oxygen and benzene on the $\mathrm{Cu} / \mathrm{HZSM} 5$-zeolite by spectroscopic methods [6-8]. The reactants mainly adsorbed on the isolated copper ions, the copper dimers and the Brønsted acid sites, showing the presence of three possible catalytic centers. While benzene adsorption reduces the $\mathrm{Cu}^{2+}$ ions to $\mathrm{Cu}^{+}$, oxygen adsorption can oxidize $\mathrm{Cu}^{+}$back to $\mathrm{Cu}^{2+}$, indicating the premise for a catalytic cycle. In zeolites with a high Al content the second charge of the divalent copper ions has to be compensated by extra-framework anions, as for example $\mathrm{OH}^{-}$. From the resonance structures $\left[\mathrm{Cu}^{2+} \mathrm{HO}^{-}\right]^{+} \leftrightarrow\left[\mathrm{Cu}^{+} \mathrm{HO}^{\bullet}\right]^{+}$the possible formation of $\mathrm{HO}^{\bullet}$ radicals may be expected, which can lead to the hydroxylation of the benzene molecule. While in the gas phase reaction no $\mathrm{HO}^{\bullet}$ radicals or hydrogen peroxide has been detected [6-8], Häusser et al. were able to demonstrate the in-situ formation of $\mathrm{HO}^{\bullet}$ radicals over $\mathrm{Cu} / \mathrm{HY}$ zeolites in aqueous suspension by spin trap and ESR experiments [9]. The detection of chlorobenzene in the product analysis of $\mathrm{Cu} / \mathrm{HZSM} 5$ zeolites which were prepared in solid state reactions with $\mathrm{CuCl}$ also shows the possibility of an ionic pathway. Chlorobenzene can be formed only in an ionic reaction with residual $\mathrm{Cl}^{-}$ions. Thus the formation of phenol can also occur via an ionic reaction with $\mathrm{HO}^{-}$ions which are, as mentioned above, also present in the zeolite.

Hence the aim of the present study is to learn more about the phenol formation on Cu/HZSM5zeolites from a mechanistic point of view. Especially the question whether phenol formation occurs over an ionic or a radical pathway is of higher interest. Therefore a number of different $\mathrm{Cu} / \mathrm{HZSM} 5$ zeolites were prepared and their catalytic properties for the benzene oxidation were observed by GC/MS-chromatography. For the product analysis Cu/HZSM5 zeolites differ in their copper loadings and their Si/Al ratios. By using nitrogen and oxygen from two separate lines, the influence of the oxygen concentration was also investigated.

Through the comparison of the product analysis from various $\mathrm{Cu} / \mathrm{HZSM} 5$-zeolites we were able to derive some interesting characteristics for the phenol formation. 


\section{Experimental details}

\subsection{Catalyst preparation}

The zeolite samples were prepared by the solid-state and the liquid ion exchange methods. To remove all organic impurities, the NaZSM5 ( $\mathrm{Si} / \mathrm{Al}=20, \mathrm{CU}$ Chemie Uetikon AG) sample was washed and calcined in air at $773 \mathrm{~K}$ for $8 \mathrm{~h}$ (heating rate: $1 \mathrm{~K} / \mathrm{min}$ ). To obtain the acid form, $2.25 \mathrm{~g}$ of the freshly calcined NaZSM5 zeolite were suspended in $1 \mathrm{M} \mathrm{NH}_{4} \mathrm{NO}_{3}$ solution, heated up to $353 \mathrm{~K}$ and stirred for $6 \mathrm{~h}$. Afterwards the zeolite was filtered off and calcined in air at $773 \mathrm{~K}$ overnight. This procedure was repeated twice with the obtained HZSM5 zeolite. The HZSM5 zeolite with a Si/Al ratio of 50 was directly available in its acid form (CU Chemie Uetikon AG). The Cu-containing catalysts were prepared by mixing the desired amount of $\mathrm{CuCl}$ with $\mathrm{HZSM} 5$, followed by calcination in a nitrogen flow $(80 \mathrm{ml} / \mathrm{min}$ ) for $16 \mathrm{~h}$. The amount of introduced $\mathrm{Cu}$ ions was calculated in proportion to the available acid sites in the zeolite $\left(\mathrm{Cu}^{+} / \mathrm{H}^{+}\right.$ratio). In this work the $\mathrm{Cu}^{+} / \mathrm{H}^{+}$ratio and the Si/Al ratio of the zeolites will be labeled after the zeolite name. For example a $\mathrm{Cu} / \mathrm{HZSM} 5$ zeolite with $\mathrm{a}^{+} \mathrm{Cu}^{+} / \mathrm{H}^{+}$ ratio of 0.50 and a Si/Al ratio of 20 is listed as Cu/HZSM5- $(0.5,20)$. To obtain the liquid ion exchanged $\mathrm{Cu} / \mathrm{HZSM} 5,0.5 \mathrm{~g}$ of the calcined HZSM5 were suspended in $0.1 \mathrm{M} \mathrm{Cu}\left(\mathrm{NO}_{3}\right)_{2}$ solution. The suspension was heated up to $353 \mathrm{~K}$ for $8 \mathrm{~h}$. Afterwards, the zeolite was filtered off and calcined at $1123 \mathrm{~K}$ in a nitrogen flow $(80 \mathrm{ml} / \mathrm{min})$ for $16 \mathrm{~h}$. To remove the acid sides from the zeolite, the Cu/HZSM5-zeolite was washed with $0.1 \mathrm{M} \mathrm{KOH}$ solution and calcined for $16 \mathrm{~h}$ at $1023 \mathrm{~K}$ in a nitrogen flow $(80 \mathrm{ml} / \mathrm{min})$.

\subsection{Gas phase oxidation of benzene with molecular oxygen}

The benzene oxidation was carried out in a continuous flow reactor at different temperatures (623 K - $823 \mathrm{~K}$ ). The purity of benzene (Uvasol ${ }^{\circledR}$, Merck KGaA) was checked by gas chromatography and used without further purification. Nitrogen and oxygen were used as received. Before starting the reaction, all catalysts were activated using the following temperature program [2]. About $25 \mathrm{mg}$ of the zeolite were heated up to $773 \mathrm{~K}$ in flowing air ( $\mathrm{N}_{2}$ flow: $32 \mathrm{ml} / \mathrm{min}, \mathrm{O}_{2}$ flow: $8 \mathrm{ml} / \mathrm{min}$ ) with a heating rate of $1 \mathrm{~K} / \mathrm{min}$. After $2 \mathrm{~h}$ at $773 \mathrm{~K}$ the reactor was purged with nitrogen ( $\mathrm{N}_{2}$ flow: $80 \mathrm{ml} / \mathrm{min}$ ) for 30 minutes and the reactor was tempered on the desired reaction temperature (typically $723 \mathrm{~K}$ ). To start the reaction a nitrogen flow of $10 \mathrm{ml} / \mathrm{min}$ was passed through a saturator filled with benzene and directly linked to the reactor. From two separate lines more nitrogen and oxygen were conducted to the reactor to obtain the chosen $\mathrm{N}_{2} / \mathrm{O}_{2}$ ratio (normally $\mathrm{N}_{2}: \mathrm{O}_{2}=4: 1$ by volume ratio).

The exit of the reactor was directly linked to a HP 6890 G1540A gas chromatograph equipped with a HP 5973 mass spectrometer. To separate the organic reaction products a $30 \mathrm{~m} \mathrm{HP-5}$ capillary column packed with diphenyl- (5\%) and dimethylsiloxane (95\%) was used. The identification of the organic products was carried out by mass spectrometry. The gaseous reaction products (and reactants) were separated by a HP-POLT capillary $(30 \mathrm{~m})$ and a HP-MOLESIEVE $(30 \mathrm{~m})$ capillary column and identified with a TCD detector. All lines were heated to prevent the condensation of benzene and the reaction products. He was used as carrier gas for all columns. Typically, the first product analysis was carried out $5 \mathrm{~min}$ after starting the reaction, and then every $30 \mathrm{~min}$. The contact time of the reactants on the catalysts was $0.12 \mathrm{~s}$. 


\section{Results and discussion}

\subsection{Choice of the reaction temperature}

In previous studies the phenol formation on the $\mathrm{Cu} / \mathrm{HZSM} 5$ could be observed even at temperatures below $373 \mathrm{~K}$ [8]. However the strong interaction between the copper centers and the benzene molecules resulted in a problem for the product desorption. At moderate temperatures, the adsorbed benzene and the products are hard to remove from the zeolite, leading to the deactivation of the catalysts. A higher product and benzene desorption can be achieved by increasing the reaction temperature, but this has the disadvantage of promoting the full oxidation of benzene to $\mathrm{CO}$ and $\mathrm{CO}_{2}$. To find a good compromise between the desorption and the full oxidation of the reactants, the benzene conversion was carried out on $\operatorname{Cu} / \operatorname{HZSM} 5-(0.5,20)$ at several reaction temperatures between $573 \mathrm{~K}$ and $773 \mathrm{~K}$. The best result was achieved at a temperature of $723 \mathrm{~K}$. Therefore, further reactions were carried out at a reaction temperature of $723 \mathrm{~K}$.

\subsection{The role of copper}

To learn more about the role of copper, the benzene conversion was carried out on a copper-free HZSM5- $(0,20)$ and a copper containing $\operatorname{Cu} / \operatorname{HZSM5}-(0.27,20)$ zeolite under the same reaction

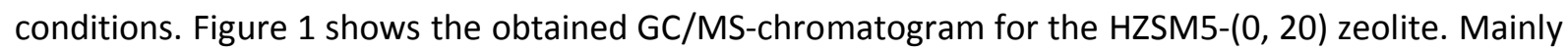
four reaction products were observed. Toluene (retention time $\left.t_{R}=4.5 \mathrm{~min}\right)$, styrene $\left(t_{R}=6.9 \mathrm{~min}\right.$ ) and naphthalene $\left(t_{R}=11.7 \mathrm{~min}\right)$ were formed in small amounts, while diphenylmethane $\left(t_{R}=15 \mathrm{~min}\right)$ was the main product of the benzene conversion. No oxidation products like $\mathrm{CO}_{2}$ or $\mathrm{CO}$ were detected in the corresponding GC-chromatogram (figure not shown.).

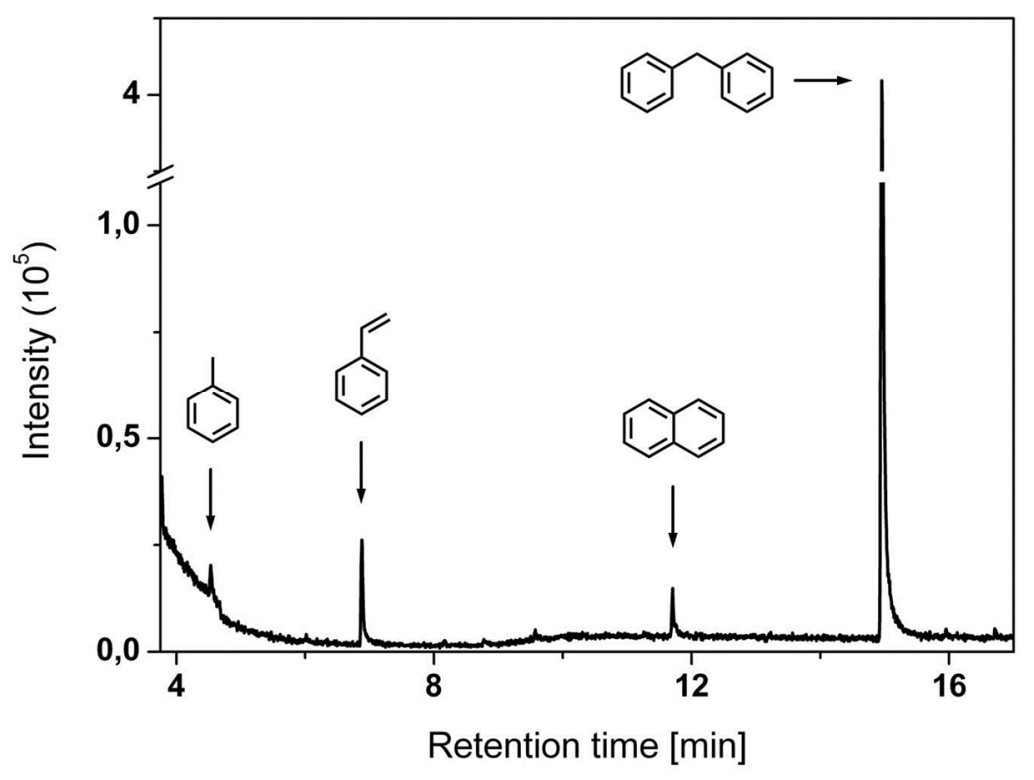

Figure 1. GC/MS chromatogram of product selectivity for the benzene conversion over HZSM5- $(0,20)$ zeolite at a reaction temperature of $723 \mathrm{~K}$ and an $\mathrm{O}_{2}$ and $\mathrm{N}_{2}$ flow of 8 and $32 \mathrm{ml} / \mathrm{min} 30$ minutes after the beginning of the reaction. Note the change of scale at an intensity of $1.1 \times 10^{5}$. 
<smiles>Cc1ccccc1</smiles>

Toluene

6<smiles>Oc1ccccc1</smiles>

Phenol<smiles>Clc1ccccc1</smiles>

Chlorobenzene<smiles>C=Cc1ccccc1</smiles>

Styrene

8<smiles>C#Cc1ccc(C)cc1</smiles>

1-Ethynyl-4-methyl -benzene

12<smiles>c1ccc(-c2ccccc2)cc1</smiles>

Biphenyl<smiles>c1ccc(Cc2ccccc2)cc1</smiles>

Biphenylmethane<smiles>O=C1C=CC(=O)C=C1</smiles>

Benzoquinone 9<smiles>c1ccc2ccccc2c1</smiles>

Naphthalene $-1-\mathrm{H}$-inden-1-one<smiles>O=C1CCc2ccccc21</smiles>

\section{2,3-Dihydro}

13<smiles>c1ccc2c(c1)oc1ccccc12</smiles>

Dibenzofuran

Scheme 1. Overview over the obtained products

A different product formation is observed for the $\mathrm{Cu} / \mathrm{HZSM} 5-(0.27,20)$ zeolite (figure 2). Many new products like phenol (peak 6), benzoquinone (peak 4) or benzofuran (peak 7) were observed besides the products which were seen on $\operatorname{HZSM5}-(0,20)$. The assignment of the numbered peaks of figure 2 is based on scheme 1. Small traces of $\mathrm{CO}$ and $\mathrm{CO}_{2}$ were detected in the GC-chromatogram of the $\mathrm{Cu} /$ HZSM5- $(0.27,20)$ zeolite. The main difference between this two product distributions is the

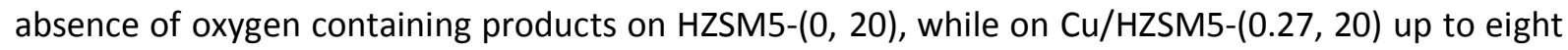
(including $\mathrm{CO}$ and $\mathrm{CO}_{2}$ ) different oxygen containing products were identified. This observation leads to the conclusion that the oxygen activation takes place on the copper centers of $\mathrm{Cu} / \mathrm{HZSM} 5-(0.27$, 20). A possible reactive species could be the superoxide anion $\mathrm{O}_{2}{ }^{\circ-}$, which can be formed in two different ways on $\mathrm{Cu} / \mathrm{HZSM} 5[8,10]$. In the first case, the adsorption of oxygen on $\mathrm{Cu}^{+}$leads to the oxidation of $\mathrm{Cu}^{+}$to $\mathrm{Cu}^{2+}$ under the formation of a $\left[\mathrm{Cu}^{2+}-\mathrm{O}_{2}{ }^{--}\right]$complex according to

$$
\mathrm{Cu}^{+}+\mathrm{O}_{2} \rightarrow\left[\mathrm{Cu}^{2+}-\mathrm{O}_{2}^{\bullet-}\right]^{+}
$$




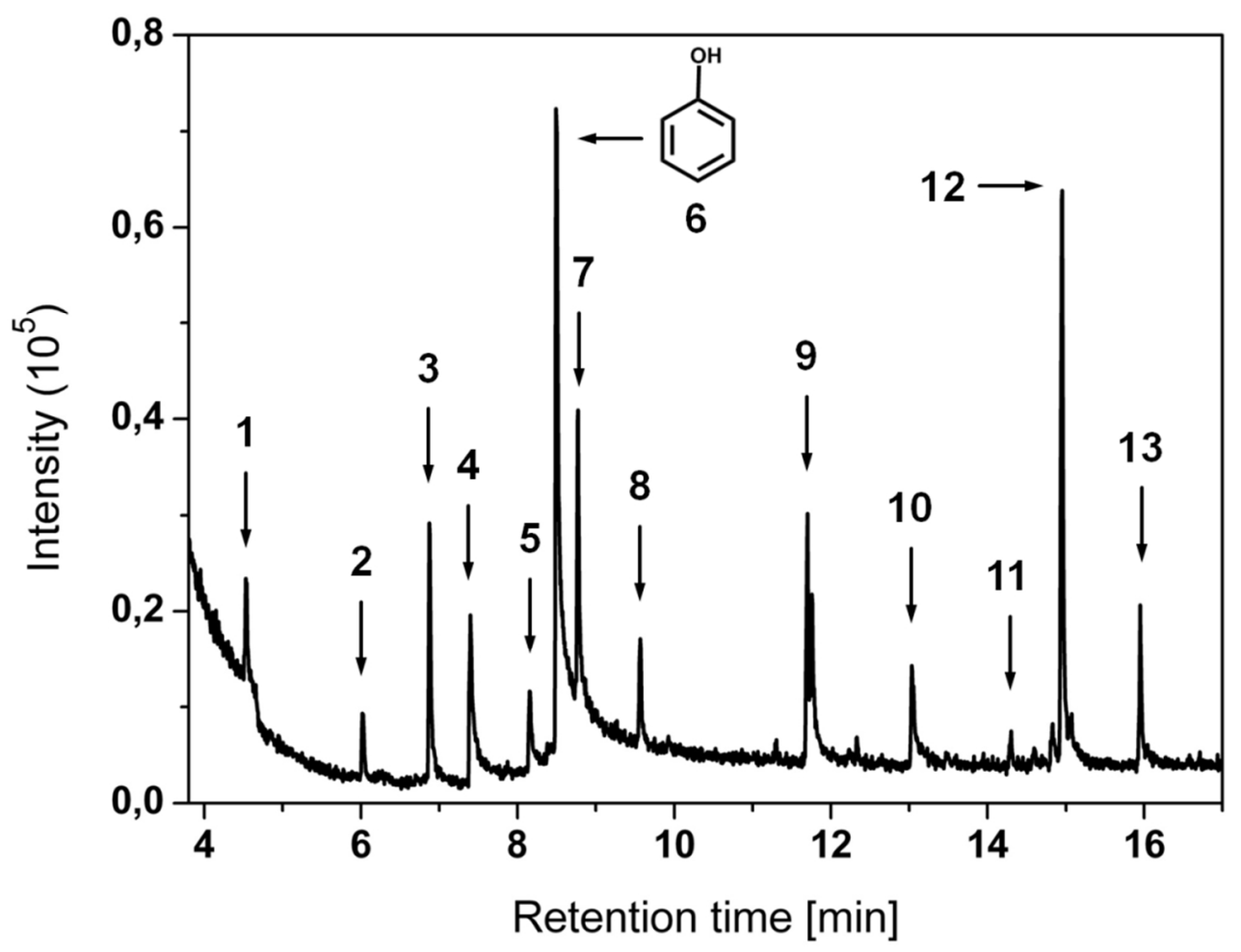

Figure 2. GC/MS chromatogram of product selectivity for the benzene conversion over Cu/HZSM5-(0.27, 20) zeolite at a reaction temperature of $723 \mathrm{~K}$ and an $\mathrm{O}_{2}$ and $\mathrm{N}_{2}$ flow of 8 and $32 \mathrm{ml} / \mathrm{min} 30$ minutes after the beginning of the reaction. Peak assignment: 1: toluene, 2: chlorobenzene, 3: styrene, 4: benzoquinone, 5 : benzaldehyde, 6: phenol, 7: benzofuran, 8: 1-ethynyl-4-methyl-benzene, 9: naphthalene, 10: 2,3-dihydro,1- $\mathrm{H}-$ Inden-1-one, 11: biphenyl, 12: biphenylmethane, 13: dibenzofuran.

On the other hand, $\mathrm{Cu}^{2+}$ is reduced back to $\mathrm{Cu}^{+}$by benzene [6]

$$
\mathrm{Cu}^{2+}+\mathrm{C}_{6} \mathrm{H}_{6} \rightarrow \mathrm{Cu}^{+}+\mathrm{C}_{6} \mathrm{H}_{6}^{+}
$$

which closes the catalytic redox cycle on $\mathrm{Cu}$. The benzene radical cation has been observed previously in $\mathrm{Cu} / \mathrm{HZSM} 5$ by electron paramagnetic resonance spectroscopy [6].The second possibility is the cleavage of a $\left[\mathrm{Cu}^{2+}-\mathrm{O}_{2}{ }^{2-}-\mathrm{Cu}^{2+}\right]$ peroxo complex in the presence of oxygen:

$$
\left[\mathrm{Cu}^{2+}-\mathrm{O}_{2}{ }^{2-}-\mathrm{Cu}^{2+}\right]+\mathrm{O}_{2} \rightarrow 2\left[\mathrm{Cu}^{2+}-\mathrm{O}_{2}^{\bullet-}\right]^{+}
$$

These di-copper complexes can also be present in Cu/HZSM5 zeolites with high Al and Cu content [11]. The isolated $\mathrm{Cu}$ ions and the peroxo di-copper complex were both mentioned previously in literature in context with oxygen activation $[3,12,13]$. Hamada et al. suggested isolated, squarepyramidal $\mathrm{Cu}^{2+}$ ions to be the active sites for the phenol formation on $\mathrm{Cu} / \mathrm{HZSM} 5$ zeolites [3]. The mechanism of oxygen activation on di-copper complexes was studied for the enzyme tyrosinase [12, 13], and the $\mathrm{Cu}-\mathrm{Cu}$ distance in $\mathrm{Cu} / \mathrm{HZSM} 5$ was found to be similar to that in tyrosinase [7], suggesting that oxidation on a zeolite may occur by the same mechanism as in the enzyme. This aspect was not in the focus of the present study which does not discriminate between and oxygen activation on dicopper complexes and on isolated ions.

Spin trap experiments with DMPO for the benzene oxidation on Cu/HZSM5 zeolites in cyclohexane have revealed the formation of phenyl peroxy radicals ( $\mathrm{PhOO}^{\circ}$ ) and phenoxy radicals (PhO ${ }^{\circ}$ ) [14]. 
Their formation was assigned to the superoxide anion. According to eqn. (4) a superoxide anion can react with a benzene radical cation from the benzene adsorption to form a phenyl peroxy radical. Furthermore, two $\mathrm{PhOO}^{\bullet}$ radicals can dimerize and via elimination of dioxygen two $\mathrm{PhO}{ }^{\bullet}$ radicals can be formed $[15,16]$ :

$$
\begin{aligned}
& \mathrm{C}_{6} \mathrm{H}_{6}{ }^{\bullet+}+\left[\mathrm{Cu}^{2+}-\mathrm{O}_{2}{ }^{--}\right]^{+} \underset{-\mathrm{H}^{+}}{\longrightarrow} \mathrm{C}_{6} \mathrm{H}_{5} \mathrm{OO} 0^{\bullet}+\mathrm{Cu}^{+}, \\
& 2 \mathrm{C}_{6} \mathrm{H}_{5} \mathrm{OO} \rightarrow\left(\mathrm{C}_{6} \mathrm{H}_{5} \mathrm{OO}\right)_{2} \rightarrow 2 \mathrm{C}_{6} \mathrm{H}_{5} \mathrm{O}^{\bullet}+\mathrm{O}_{2} .
\end{aligned}
$$

To which extent these results can be transferred to the gas phase reaction still has to be clarified, but they show the potential of the superoxide anions as a reactive species in the present context. Furthermore, these observations indicate that phenol formation in the gas phase reaction can occur by a different reaction mechanism than in aqueous solution $[1,9]$.

These results also show that the $\mathrm{Cu} / \mathrm{HZSM} 5$ zeolite has catalytic properties which are independent of the copper centers. The formation of carbonaceous compounds (coke) is catalyzed by the presence of Brønsted acid sites in the zeolite. In order to achieve a high phenol yield and a high selectivity towards phenol it will be a challenging task to suppress the formation of coke.

\subsection{The influence of the copper concentration}

To learn more about the role of copper and the influence of the copper concentration, seven $\mathrm{Cu} / \mathrm{HZSM} 5$ zeolites $(\mathrm{Si} / \mathrm{Al}=20$ ) with different amounts of copper loadings were prepared and their catalytic properties for the benzene conversion were investigated. Figure 3 shows the product analysis for the $\mathrm{Cu} / \mathrm{HZSM} 5-(1.02,20)$ and the $\mathrm{Cu} / \mathrm{HZSM} 5-(0.27,20)$ catalyst. The use of $\mathrm{Cu} / \mathrm{HZSM} 5-$ $(0.27,20)$ as catalyst leads to more phenol and biphenylmethane than the Cu/HZSM5-(1.02, 20) zeolite, while chlorobenzene (peak 2), naphthalene (peak 9) and biphenyl (peak 11) were preferably formed on the $\mathrm{Cu} / \mathrm{HZSM} 5-(1.02,20)$ zeolite. Chlorobenzene is formed in an ionic reaction with chloride ions which remained in the zeolite after the solid state exchange with $\mathrm{CuCl}$. Thus, more chlorobenzene is formed for higher copper loadings. The products naphthalene and biphenyl can be assigned to the formation of the benzene radical cation intermediate. Two of the radical cations can react with each other to form biphenyl. Because the benzene concentration is much higher than the benzene radical cation concentration, it is also possible that biphenyl is formed in a reaction with a single radical cation and a benzene molecule:

$$
\begin{aligned}
& \mathrm{Cu}^{2+}+\mathrm{C}_{6} \mathrm{H}_{6} \rightarrow \mathrm{Cu}^{+}+\mathrm{C}_{6} \mathrm{H}_{6}{ }^{\bullet+}, \\
& 2 \mathrm{C}_{6} \mathrm{H}_{6}^{\bullet+} \rightarrow \text { Biphenyl }+2 \mathrm{H}^{+} \text {or } \mathrm{C}_{6} \mathrm{H}_{6}^{\bullet+}+\mathrm{C}_{6} \mathrm{H}_{6} \rightarrow \text { Biphenyl }+2 \mathrm{H}^{+}+\mathrm{e}^{-} .
\end{aligned}
$$




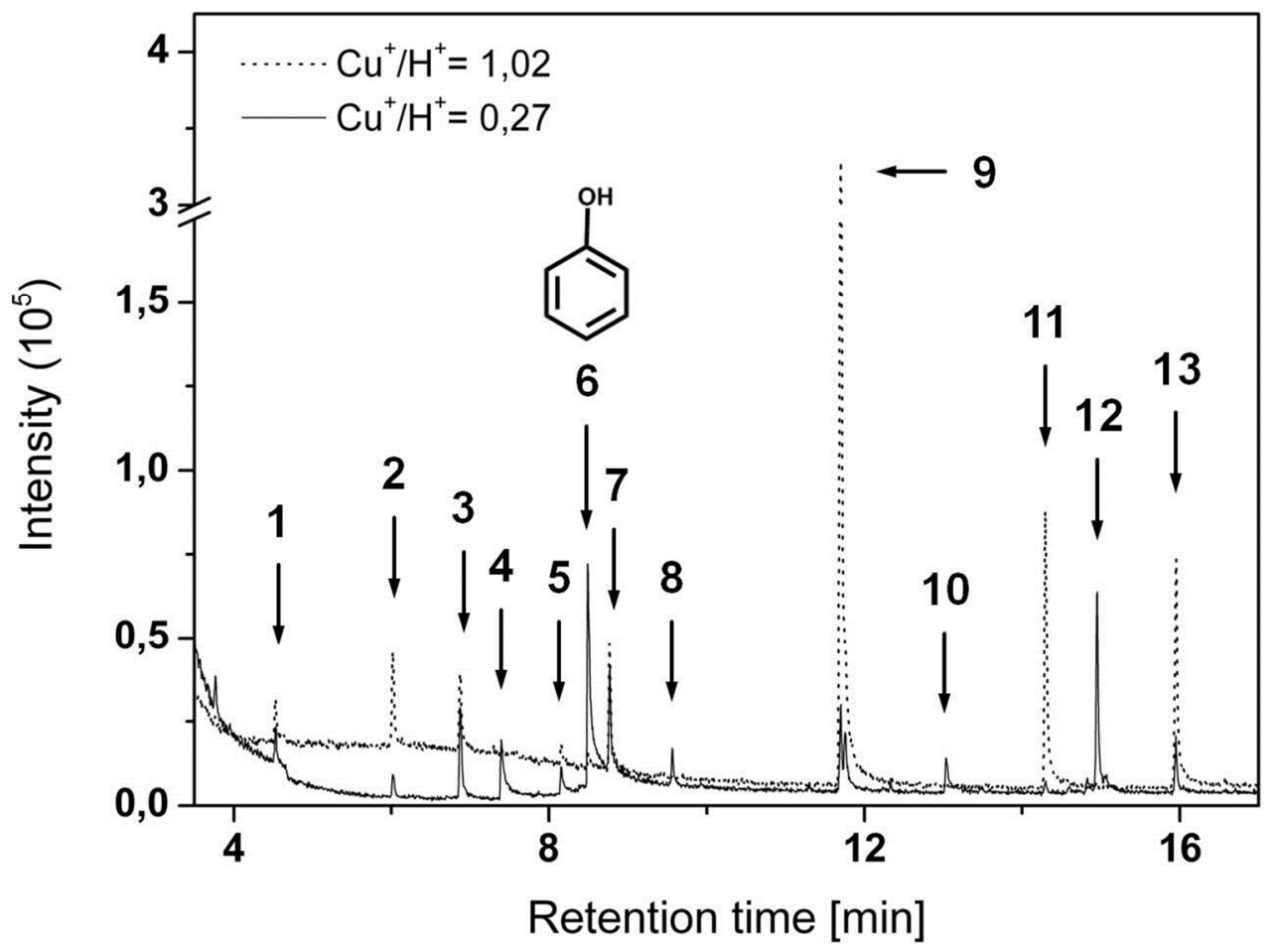

Figure 3. GC/MS chromatogram of product selectivity for the benzene conversion over Cu/HZSM5-(1.02, 20) (dotted line) and $\mathrm{Cu} / \mathrm{HZSM} 5-(0.27,20)$ (full line) at a reaction temperature of $723 \mathrm{~K}$ and an $\mathrm{O}_{2}$ and $\mathrm{N}_{2}$ flow of 8 and $32 \mathrm{ml} / \mathrm{min}, 30$ minutes after the beginning of the reaction. Note the change of scale at an intensity of $2 \times$ $10^{5}$ (assignment of peaks as in Scheme 1 and Figure 2).

The formation of naphthalene via a radical mechanism seems also to be thermodynamically more favored than via a possible condensation reaction [16]. It is obvious that a high copper concentration leads to a high concentration of benzene radical cations which are finally responsible for the high amounts of naphthalene and biphenyl products on Cu/HZSM5-(1.02, 20). The formation of phenol is more favored on $\mathrm{Cu} / \mathrm{HZSM} 5$ with smaller amounts of copper. The catalysts which provide the best yields of phenol can be identified from figure 4. Obviously, the obtained amounts of phenol were not as high as it has been reported in literature [3-5]. However the main aim of this study is to understand the reaction mechanism on a molecular scale, so the small yields of phenol did not diminish our results. Thus, the highest phenol yield was obtained on Cu/HZSM5-(0.27, 20). 


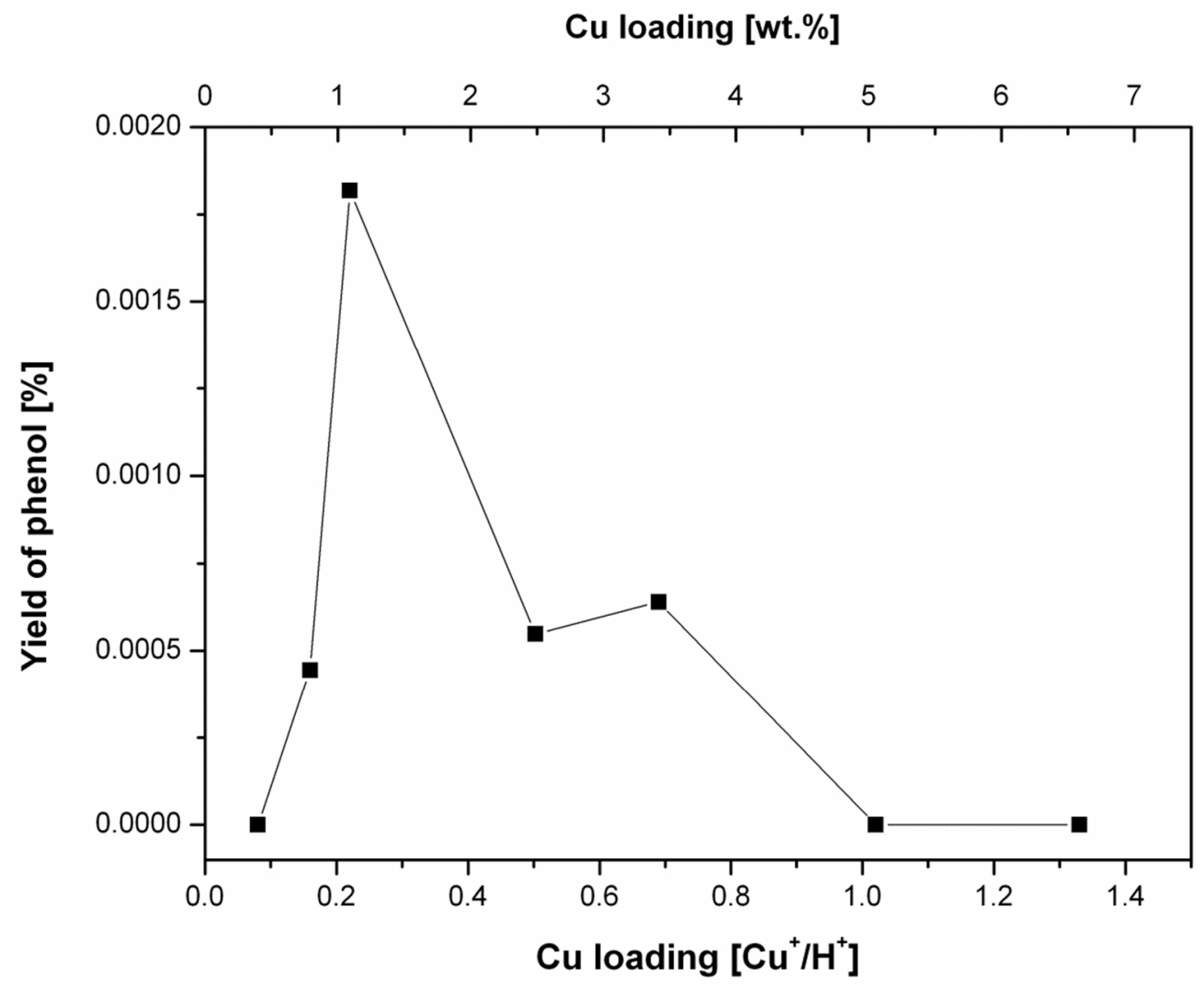

Figure 4. Yield of phenol in dependence of the copper loading. Product analysis was carried out 30 minutes after the start of the reaction which was conducted under identical reaction conditions (reaction temperature: $723 \mathrm{~K}, \mathrm{O}_{2}$ flow: $8 \mathrm{ml} / \mathrm{min}$ and $\mathrm{N}_{2}$ flow: $32 \mathrm{ml} / \mathrm{min}$ ).

The amount of the deep oxidation products $\mathrm{CO}$ and $\mathrm{CO}_{2}$ were also investigated in dependence of the copper loading. Figure 5 shows the total consumption of oxygen and the formation of $\mathrm{CO}_{2}$ and $\mathrm{CO}$. It is obvious that a high copper loading promotes the formation of the deep oxidation products. These results correspond with the result of oxygen activation on the copper centers and with the observation that was made previously in literature [3-5]. The more copper centers are available in the zeolite the more oxygen molecules can be activated. Consequently, for a high amount of formed phenol a catalyst with a lower copper loading is more suitable than a catalyst with a high copper loading. 


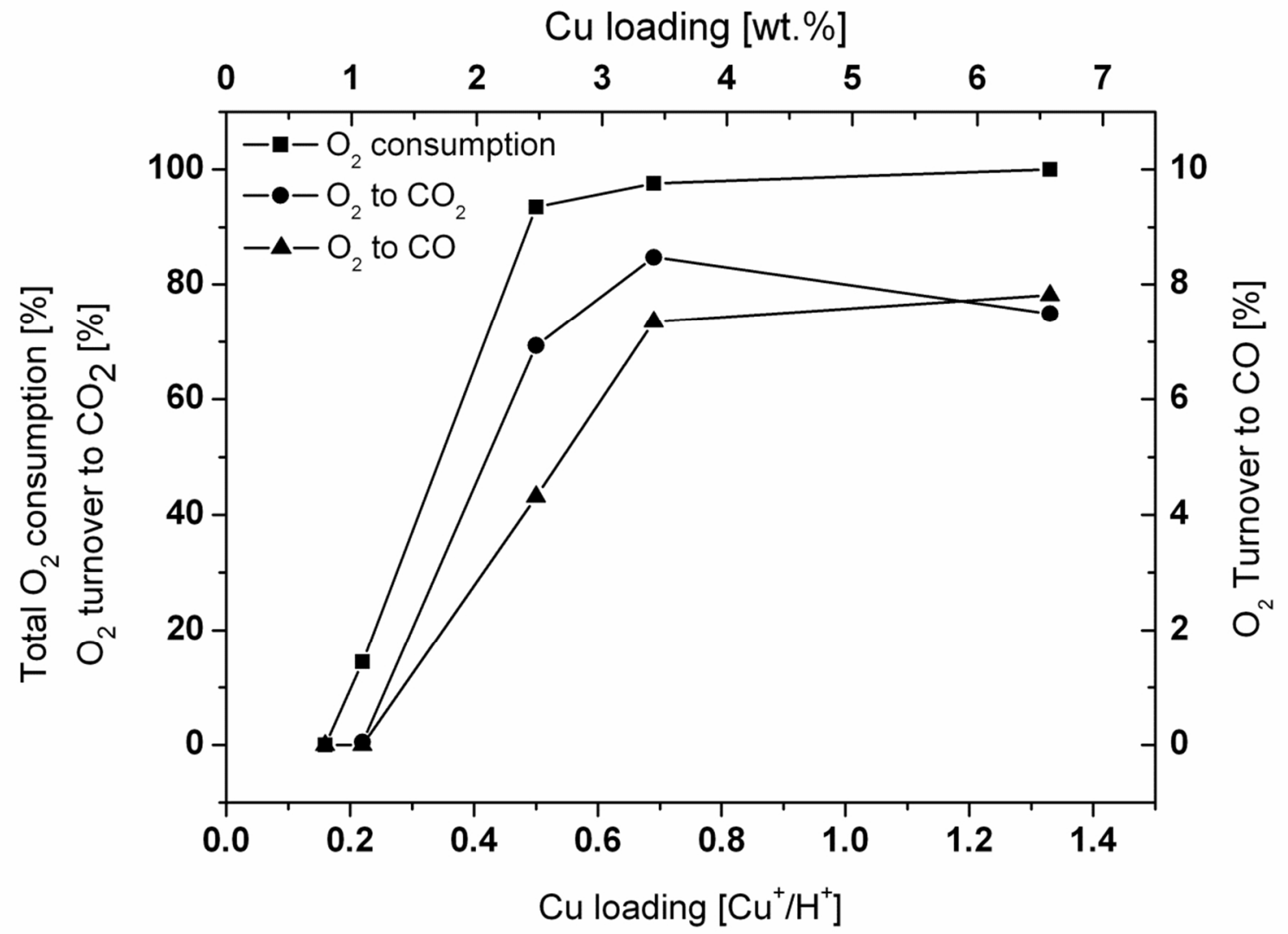

Figure 5. Consumption of $\mathrm{O}_{2}$ and its turnover to $\mathrm{CO}_{2}$ and $\mathrm{CO}$. Product analysis was carried out 30 minutes after the start of the reaction which was carried out under identical reaction conditions (reaction temperature: 723 $\mathrm{K}, \mathrm{O}_{2}$ flow: $8 \mathrm{ml} / \mathrm{min}$ and $\mathrm{N}_{2}$ flow: $32 \mathrm{ml} / \mathrm{min}$ ). Note the two different $\mathrm{y}$-scales.

\subsection{The role of the Brønsted acid sites}

To investigate the role of the Brønsted acid sites, three $\mathrm{Cu} / \mathrm{HZSM} 5$ zeolites with different copper loadings were washed with a $0.1 \mathrm{M} \mathrm{KOH}$ solution, and their catalytic properties for the phenol formation was also studied by GC/MS-chromatography. Representative for all three zeolites, figure 6 shows the GC/MS chromatogram for the $\mathrm{KOH}$ treated $\mathrm{Cu} / \mathrm{HZSM} 5-(0.69,20)$ (listed below as $\mathrm{Cu} / \operatorname{KZSM} 5-(0.69,20))$ and for the $\mathrm{KOH}$ untreated $\mathrm{Cu} / \mathrm{HZSM} 5-(0.69,20)$. There are significant differences between these two chromatograms. Only four different products were detected on the $\mathrm{Cu} / \operatorname{KZSM} 5-(0.69,20)$ zeolite (benzoquinone (peak 4), benzaldehyde (peak 5), benzofuran (peak 7) and chlorobenzene (peak 2)), while on the $\operatorname{Cu} / \operatorname{HZSM} 5-(0.69,20)$ zeolite ten different products were formed. The detection of chlorobenzene shows that it is not possible to remove the chloride anions just through washing the zeolite with $\mathrm{KOH}$. Another very interesting observation is that no plain hydrocarbon products like styrene (peak 3) and naphthalene (peak 9) were formed on the $\mathrm{Cu} / \operatorname{KZSM} 5-(0.69,20)$ zeolite. This observation, linked with the observation that was made on the plain HZSM5-(20) zeolite, demonstrate the catalytic properties of the Brønsted acid sites. The acid sites promote the cracking of the benzene molecule and the combination of the derived fragments. Elemental analysis and FTIR measurements were performed for both zeolites to verify the removal of the Brønsted acid according to eqn. (8),

$$
\mathrm{H}^{+} \mathrm{ZM}^{-}+\mathrm{KOH} \rightarrow \mathrm{K}^{+} \mathrm{ZSM}^{-}+\mathrm{H}_{2} \mathrm{O} .
$$




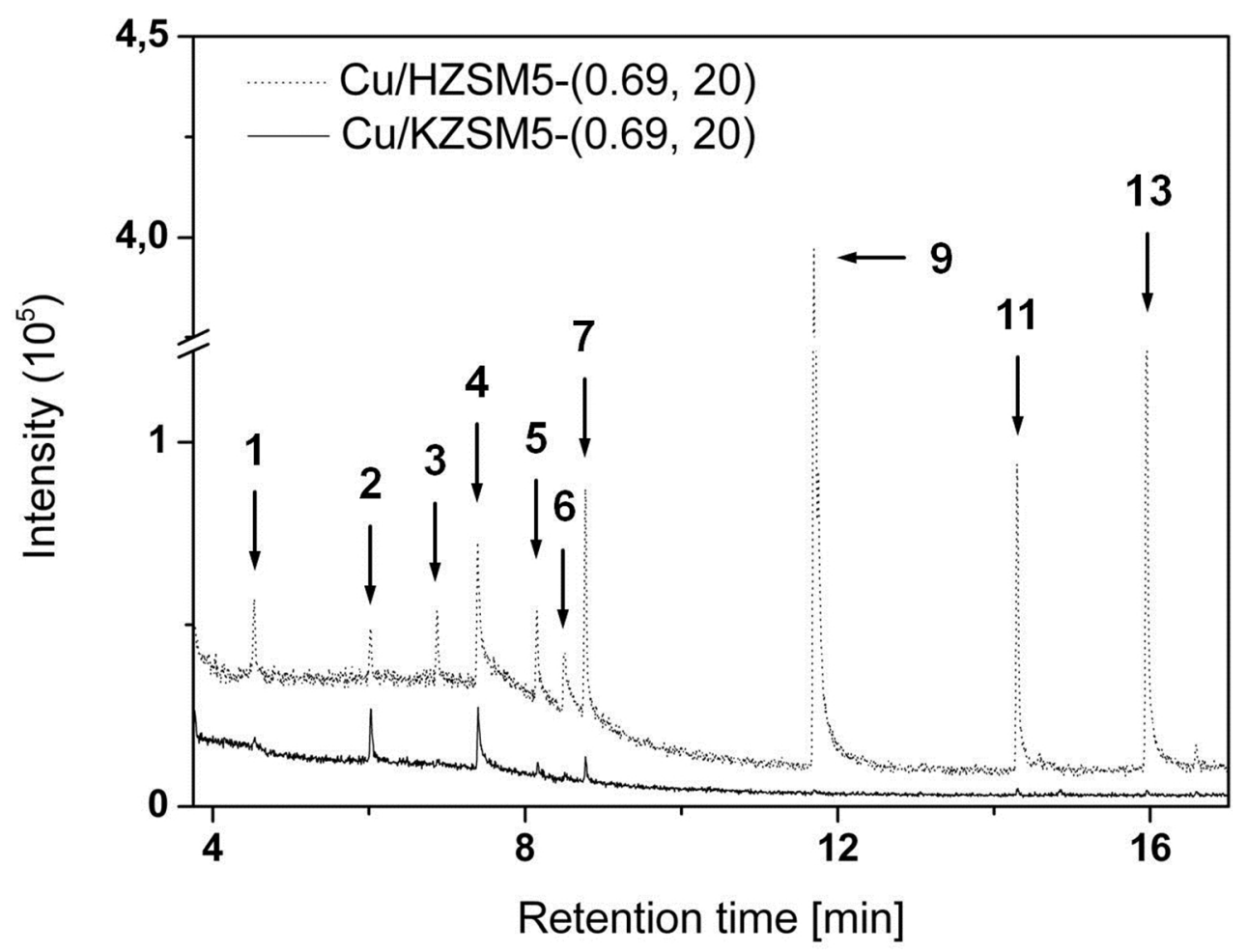

Figure 6. GC/MS chromatogram of product selectivity for the benzene conversion over the Cu/HZSM5-(0.69, 20) (dotted line) and the $\mathrm{Cu} / \operatorname{KZSM} 5-(0.69,20)$ zeolite (full line) at a reaction temperature of $723 \mathrm{~K}$ and an $\mathrm{O}_{2}$ and $\mathrm{N}_{2}$ flow of 8 and $32 \mathrm{ml} / \mathrm{min}, 30$ minutes after the start of the reaction. Note the change of scale at an intensity of $1.5 \times 10^{5}$ (assignment of peaks as in Figure 2).

The elemental analysis showed an increase of $\mathrm{K}$ from 0 to 3.94 wt.\%, while the FTIR-measurements showed a loss of the corresponding $\mathrm{Al}(\mathrm{OH})$ - and Brønsted acid lines at wavenumbers of 3667 and $3611 \mathrm{~cm}^{-1}$ (figure not shown). The fact that on the $\mathrm{Cu} / \operatorname{KZSM} 5-(0.69,20)$ zeolite no phenol was detected leads to the conclusion that the Brønsted acid sites are also important for the phenol formation on the $\mathrm{Cu} / \mathrm{HZSM} 5$ zeolites. This indicates the bifunctionality of the $\mathrm{Cu} / \mathrm{HZSM} 5$ zeolite. This result agrees also with the observation of the spin trap experiments. By comparing the spin trap adducts on $\mathrm{Cu} / \mathrm{HZSM} 5$ with the adducts of the $\mathrm{Cu} / \mathrm{NaZSM} 5$ zeolite, Kromer et al. showed that the overall spin concentration on the sodium form of the zeolite is nearly three orders of magnitude less than on Cu/HZSM5 [14]. The Brønsted acid sites are essential for the formation of radical cations from unsaturated organic molecules, although the exact nature of the reaction mechanism is not well understood [17].

\subsection{The influence of the Si/Al ratio}

To investigate the catalytic influence of the Si/Al ratio, $\mathrm{Cu} / \mathrm{HZSM} 5$ zeolites with different Si/Al ratios (20 and 50) were prepared. For better comparability roughly the same $\mathrm{Cu}^{+} / \mathrm{H}^{+}$ratio $(0.27$ and 0.30$)$ was chosen. The GC/MS-chromatogram for the Cu/HZSM5- $(0.30,50)$ zeolite is shown in figure 7. A different product spectrum is observed on $\mathrm{Cu} / \mathrm{HZSM} 5-(0.27,20)$ (compare figure 2 ). In particular less of the oxygen containing products benzoquinone (peak 4), benzaldehyde (peak 5), and phenol (peak 
6) but more benzofuran (peak 7) is formed than on the $\mathrm{Cu} / \mathrm{HZSM} 5-(0.27,20)$ while the formation of the deep oxidation products is highly increased (figure 8). This observation is quite remarkable, as the total amount of copper in $\mathrm{Cu} / \mathrm{HZSM} 5-(0.30,50)$ is smaller than on $\mathrm{Cu} / \mathrm{HZSM} 5-(0.27,20)$. Since it was shown that the oxygen activation takes place at the copper center, a higher copper content is expected to lead to more oxygen activation which should therefore lead to more of the deep oxidation product, but the opposite behavior is observed. The main difference between these two zeolites is the number of possible adsorption centers. Based on the low Al content the probability to find two Al atoms in the Cu/HSZM5- $(0.30,50)$ next to each other is smaller than on the Cu/HZSM5$(0.27,20)$ zeolite [18]. This means that the charge compensation of the divalent $\mathrm{Cu}^{2+}$ and copperoxocation species on the $\mathrm{Cu} / \operatorname{HZSM} 5-(0.30,50)$ zeolite has to occur via extra framework anions, which can lead to the different catalytic properties. On the other hand it has already been shown that the $\mathrm{Cu} / \mathrm{HZSM} 5$ zeolite is a bifunctional catalyst, which means that the reactants have to interact simultaneously with the copper centers and the Brønsted acid sites. Statistically, at high Si/Al ratio the two catalytic centers are more distant from each other, and it is reasonable that the bifunctional mechanism is suppressed. In line with this observation is the fact that on Cu/KZSM5 and on $\mathrm{Cu} / \operatorname{HZSM} 5-(0.30,50)$ the formation of all oxidation products (benzoquinone, $\mathrm{CO}$ and $\mathrm{CO}_{2}$ ) is more favored than on the $\mathrm{Cu} / \mathrm{HZSM} 5$ zeolite with a smaller Si/Al ratio.

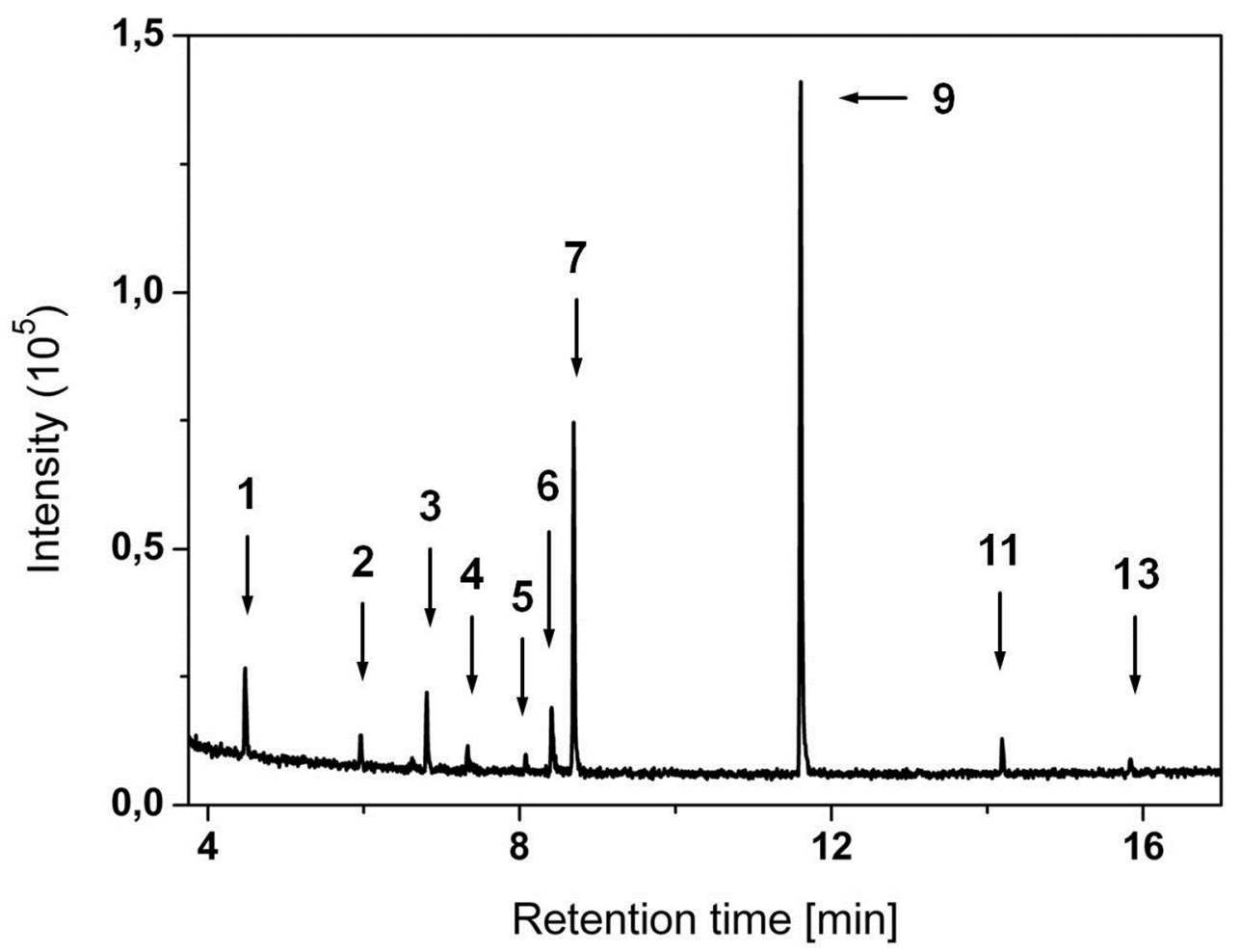

Figure 7. GC/MS chromatogram of product selectivity for the benzene conversion over the $\mathrm{Cu} / \mathrm{HZSM} 5-(0.30$, 50) zeolite at a reaction temperature of $723 \mathrm{~K}$ and an $\mathrm{O}_{2}$ and $\mathrm{N}_{2}$ flow of 8 and $32 \mathrm{ml} / \mathrm{min}, 30$ minutes after starting the reaction (assignment of peaks as in Scheme 1 and Figure 2). 


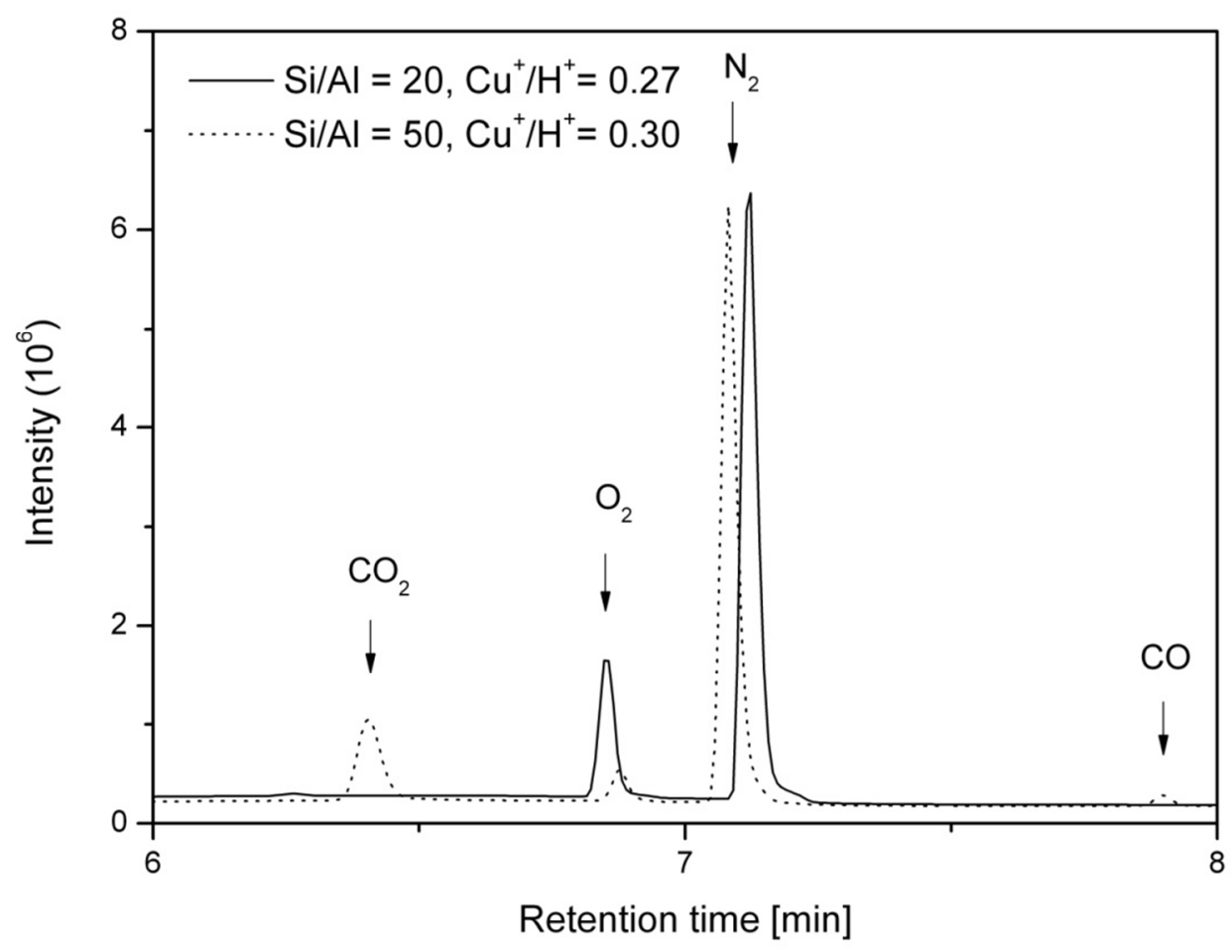

Figure 8. GC chromatograms for Cu/HZSM5 zeolites with different Si/Al-ratios 30 minutes after the start of the reaction under the same reaction conditions $\left(\mathrm{O}_{2}\right.$ flow: $8 \mathrm{ml} / \mathrm{min}, \mathrm{N}_{2}$ flow: $32 \mathrm{ml} / \mathrm{min}$, reaction temperature: 723 $\mathrm{K})$. The relative shift of the peaks is due to an exchange of the GC molecular sieve column between the two experiments.

\subsection{The influence of the oxygen concentration}

Another interesting point is the influence of the oxygen concentration of the reaction composition which is conducted over the catalyst. The Cu/HZSM5- $(0.30,50)$ zeolite showed a high affinity for the total oxidation of benzene and the question is how a reduction of the oxygen concentration will affect the product distribution. Therefore a fresh sample of the same zeolite was used for the benzene conversion with an $\mathrm{O}_{2}$ flow that was reduced from 8 to $2 \mathrm{ml} / \mathrm{min}$ while the $\mathrm{N}_{2}$ flow was raised from 32 to $38 \mathrm{ml} / \mathrm{min}$. This decrease of the $\mathrm{O}_{2}$ flow corresponds to a reduction of the oxygen excess from a factor of 68 to 17. All other reaction conditions were the same. Figure 9 shows the $\mathrm{GC} / \mathrm{MS}$-chromatogram for the smaller oxygen concentration. 


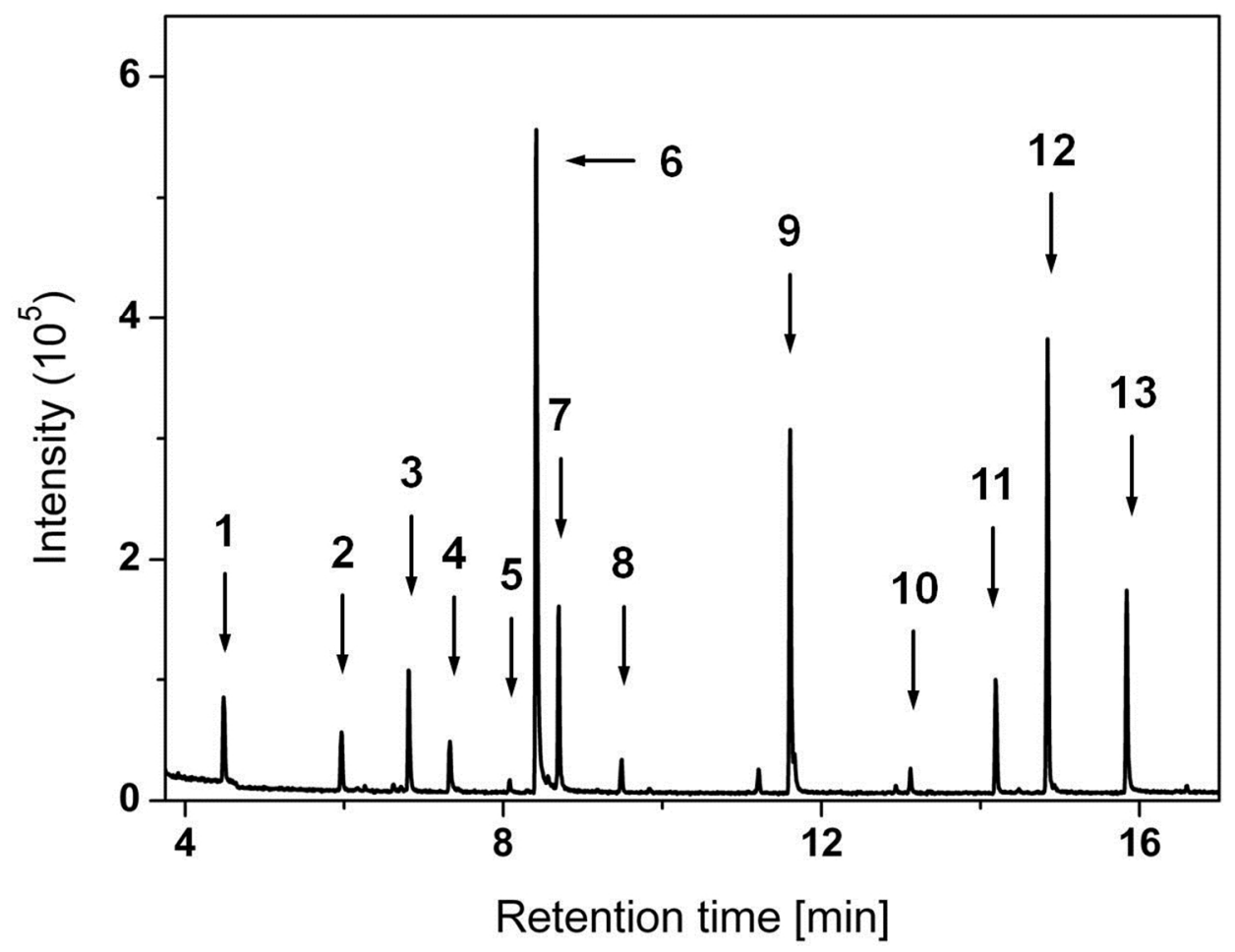

Figure 9. GC/MS chromatogram of product selectivity for the benzene conversion over $\mathrm{Cu} / \mathrm{HZSM} 5-(0.30,50)$ under a reaction temperature of $723 \mathrm{~K}$ and an $\mathrm{O}_{2}$ and $\mathrm{N}_{2}$ flow of 2 and $38 \mathrm{ml} / \mathrm{min}, 30$ minutes after starting the reaction (assignment of peaks as in Figure 2).

The obtained product distribution differs strongly from that with higher $\mathrm{O}_{2}$ flow. With a smaller oxygen concentration the total amount of products is higher than with a high oxygen concentration. The reason for this can be found in the GC chromatograms (figure 10) of both experiments. A high oxygen concentration supports the formation of $\mathrm{CO}_{2}$ and $\mathrm{CO}$ while with a low oxygen concentration only small amounts of $\mathrm{CO}_{2}$ and $\mathrm{CO}$ are formed. This observation also indicates that the activation of the oxygen molecule has to occur faster than desorption of the reaction products, which leads to the total oxidation of these products. The increase of the oxidation products by using higher $\mathrm{O}_{2}$ concentrations has been reported in literature previously [3], but this was also correlated with an increase of phenol, which is in contradiction with our present results. So for high phenol yields the $\mathrm{O}_{2}$ concentration has to be small. To which extent a stoichiometric use of oxygen is possible still has to be investigated.

For some reactions the $\mathrm{O}_{2}$ flow was turned off completely. In these cases no products containing oxygen atoms were formed, which indicates that the implemented oxygen atoms have to come from the gas and not from the zeolite framework. 


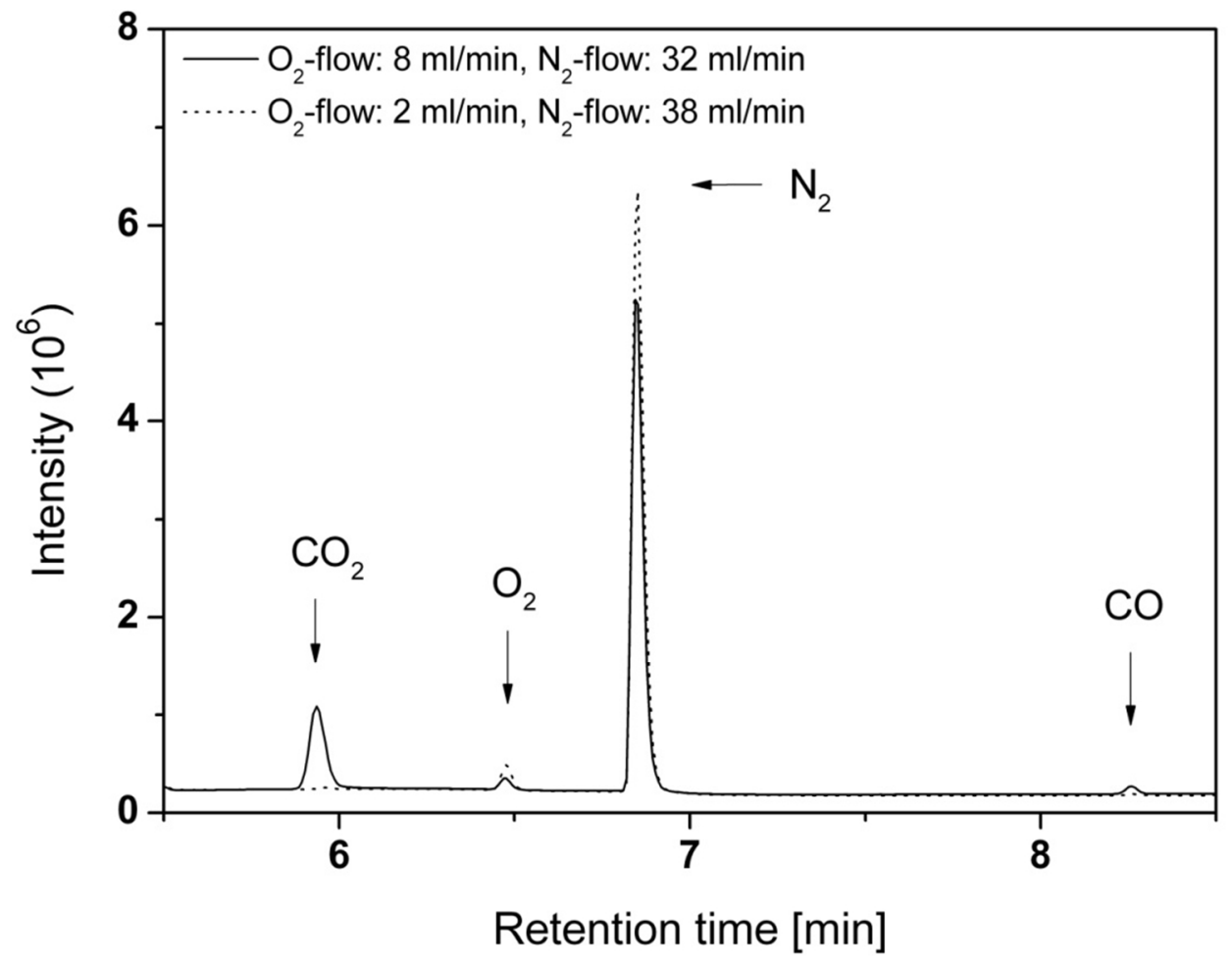

Figure 10. GC chromatogram for the benzene conversion over $\mathrm{Cu} / \mathrm{HZSM} 5-(0.30,50)$ with different oxygen and nitrogen flows. The chromatogram was recorded 30 minutes after the reaction was started at a reaction temperature of $723 \mathrm{~K}$.

After analysis of the systematic experiments the study was extended by a preliminary experiment at $\mathrm{O}_{2}$ and $\mathrm{N}_{2}$ flows of 2 and $38 \mathrm{ml} / \mathrm{min}$ in which the temperature was stepped up from $723 \mathrm{~K}$ to $823 \mathrm{~K}$. This resulted in a clear increase of the phenol yield, mostly at cost of the yield of biphenylmethane (results not shown).

\subsection{The influence of the reaction time}

For a better understanding of the process, product analyses were carried out $5 \mathrm{~min}, 30 \mathrm{~min}$ and $8 \mathrm{~h}$ after the start of the reaction. Directly after the start of the reaction $(5 \mathrm{~min}$ ) only chlorobenzene was found as product. For zeolites with a high copper loading also traces of polychlorinated benzene derivates were found. At $30 \mathrm{~min}$ the amount of chlorobenzene has decreased distinctly and product spectra as displayed in figure 2 are obtained. After $8 \mathrm{~h}$ the same products but in smaller quantities are formed, indicating the deactivation of the zeolite. The change of the color of the zeolite from light-green to dark-brown points to the formation of coke which is responsible for the deactivation of the used catalyst. To explore a possible regeneration, the used zeolite was heated up to $773 \mathrm{~K}$ under an $\mathrm{O}_{2}$ flow of 8 and a $\mathrm{N}_{2}$ flow of $32 \mathrm{ml} / \mathrm{min}$ overnight. The product analysis of benzene conversion after the heat treatment restored the same GC/MS-chromatogram as for a fresh sample but without the formation of chlorobenzene, showing regeneration of the Cu/HZSM5 zeolite is possible. Furthermore, these observations show that phenol is formed in a catalytic reaction while chlorobenzene is formed stochiometrically. 


\section{Conclusions}

The gas phase oxidation of benzene in presence of oxygen was carried out over various $\mathrm{Cu} / \mathrm{HZSM} 5$ zeolites and the product formation was studied by GC/MS chromatography. The main aim of this work was to learn more about the reaction mechanism of the phenol formation on a molecular scale, especially whether the reaction occurs via an ionic or a radical pathway. In contrast to other work which monitored only the yields of phenol, $\mathrm{CO}$ and $\mathrm{CO}_{2}, 12$ further organic products were monitored here. By using zeolites with different properties and by selective variation of reaction conditions some key conclusions can be drawn for the gas phase formation of phenol over $\mathrm{Cu} / \mathrm{HZSM} 5$-zeolites:

$>$ Alkylation and dimerization products but no oxygen-containing products were found in the absence of $\mathrm{Cu}$. The role of the copper centers in the zeolite is therefore the activation of oxygen. Whether this occurs on monomeric centers or on the oxygen-bridged copper pairs, or even at both types of centers, still has to be investigated. While Yamanaka et al suggested that $\mathrm{Cu}^{+}$species play an important role for phenol formation [2] Shibata et al. found the yield of phenol to correlate with square-pyramidal coordinated $\mathrm{Cu}^{2+}[4]$. The combination of these two conclusions is compatible with the present interpretation that the oxidation of $\mathrm{Cu}^{+}$by $\mathrm{O}_{2}$ and the reduction of $\mathrm{Cu}^{2+}$ by the adsorbed benzene represent a catalytic redox cycle.

$>$ Based on this redox cycle, the superoxide ion, $\mathrm{O}_{2}{ }^{--}$, is suggested to be a reactive intermediate in the route to phenol in a radical ionic reaction mechanism. This distinguishes the mechanism from classical phenol formation via $\mathrm{HO}^{\bullet}$ radical addition in aqueous solution [9].

$>$ No phenol was detected on zeolites without Brønsted acid sites near the copper centers, indicating the importance of bifunctionality of the $\mathrm{Cu} / \mathrm{HZSM} 5$ zeolite for this reaction. The Brønsted acid sites are essential for the formation of organic radical cations, but the exact mechanism still has to be clarified. Interestingly, other oxygenated products like benzoquinone and benzofuran were observed also in the absence of Brønsted acid sites. Earlier gas phase work did not pay specific attention to the Brønsted acid sites [2-5].

$>$ On zeolites with a high affinity for the total oxidation, the formation of deep oxidation products $\left(\mathrm{CO}, \mathrm{CO}_{2}\right)$ can be decreased by reducing the $\mathrm{O}_{2}$ flow. How far a possible stoichiometric use of $\mathrm{O}_{2}$ is possible has to be subject to further studies.

$>$ No product molecules containing oxygen were detected in the absence of $\mathrm{O}_{2}$. Thus the implemented oxygen atoms have to come from the gas-phase and not from the zeolite framework.

$>$ The formation of chlorobenzene must occur via a stoichiometric reaction with $\mathrm{Cl}^{-}$ions, but the analogous formation of phenol by reaction with $\mathrm{HO}^{-}$with benzene radical cations was not observed. Phenol is clearly formed in a catalytic reaction. Even 8 hours after the start of the reaction the same products, but in smaller yields, were detected. By heat treatment over-night, the used zeolite can be regenerated without any degradation of the catalytic properties.

Thus, while most of the observations regarding optimum reaction conditions are compatible with observations in earlier work the present study permitted a number of mechanistic conclusions. However, while the focus of the present study was on the reaction mechanism it should be noted that less than $1 \%$ of the benzene was converted in the present experiments, and the phenol yield of $0.0018 \%$ was considerably less than reported in literature (1-10\%) [3-5]. Optimum reaction temperatures were in the same range ( $723 \mathrm{~K}$ in our case and $673 \mathrm{~K}$ in literature) and also the copper loadings were similar (0.8 vs. $1.1 \%$ ), but the oxygen-to-benzene molecular ratio was much lower in 
literature (typically 5.6, compared with 68 and 17 in the present case). Significant differences are furthermore the higher Si/Al ratio in literature (30-160 [3], compared to 20 and 50 in the present work). Considering the amount of catalyst which was $25 \mathrm{mg}$ for the present experiments in a reactor of $10 \mathrm{~mm}$ inner diameter but $500 \mathrm{mg}$ in a reactor of $15 \mathrm{~mm}$ diameter in the experiments by Hamada et al. [3] at the same $\mathrm{O}_{2}$ flow the contact time is longer in literature by a factor 10 . The shorter contact time together with the higher oxygen-to-benzene ratio explains the lower yield of phenol in the present experiments.

A further origin of the small phenol yield is the strong interaction between phenol and the copper centers and hence the slow desorption from the zeolite. Higher $\mathrm{Si} / \mathrm{Al}$ ratios, i.e. less polar zeolites, permit faster desorption. A preliminary study carried out with reduced $\mathrm{O}_{2} / \mathrm{N}_{2}$ ratio to suppress the total oxidation and stepping up the temperature from $723 \mathrm{~K}$ to $823 \mathrm{~K}$ resulted in a clear rise of the total phenol yield (not shown here), which is in agreement with the findings in literature $[4,5]$ and demonstrates the complexity of this multi-parameter system. To increase the selectivity to phenol, all side reactions including total oxidation and especially the formation of coke have to be suppressed. Since the Brønsted acid sites which are needed for the formation of phenol are also responsible for the formation of coke, a compromise for the total amount of Brønsted acid sites has to be found. Higher Si/Al ratios lead to less but stronger Brønsted acid sites and the same time it destabilizes $\mathrm{Cu}^{2+}$ because charge compensation is more difficult since it may require involvement of a non-framework anion.

\section{Acknowledgment:}

Ms. Fingerle from the Institute of Technical Chemistry is kindly acknowledged for performing the elemental analysis and Mrs. Bräuning for her technical assistance with the GC/MS chromatography. Furthermore, we thank Alexander Kromer for his helpful discussion about his spin-trap experiments.

\section{References}

[1] T. Kitamura, H. Kanzaki, R. Hamada, S. Nishiyama, S. Tsuruya, Can. J. Chem. 82 (2004) 1597-1605.

[2] H. Yamanaka, R. Hamada, H. Nibuta, S. Nishiyama, S. Tsuruya, J. Molec. Catal. A: Chemical 178 (2002) 89.

[3] R. Hamada, Y. Shibata, S. Nishiyama, S. Tsuruya, Phys. Chem. Chem. Phys. 5 (2003) 956965.

[4] Y. Shibata, R. Hamada, T. Ueda, Y. Ichihashi, S. Nishiyama, S. Tsuruya, Ind. Eng. Chem. Res. 44 (2005) 8765-8772.

[5] A. Kubacka, Z. Wang, B. Sulikowski, V. C. Corberán, J. Catal. 250 (2007) 184-189.

[6] A. B. Ene, T. Archipov, E. Roduner, J. Phys. Chem. 114 (2010) 14571-14578. 
[7] A. B. Ene, M. Bauer, T. Archipov, E. Roduner, Phys. Chem. Chem. Phys. 12 (2010) 65206531.

[8] A. B. Ene, T. Archipov, E. Roduner, J. Phys. Chem. 115 (2011) 3688-3694.

[9] A. Häusser, M. Trautmann, E. Roduner, Chem. Commun. 47 (2011) 6954-6956.

[10] J. Sarkany, J. Mol. Struct. 410 (1997) 95-98.

[11] B. R. Goodman, K. C. Hass, W. F. Schneider, J. B. Adams, J. Phys. Chem. 103 (1999) $10452-12460$.

[12] A. C. Rosenzweig, M. H. Sazinsky, Curr. Opin. Struct. Biol. 16 (2006) 729-735.

[13] M. Rolff, J. Schottenheim, H. Decker, F. Tuczek, Chem. Soc. Rev. (2010).

[14] A. Kromer, E. Roduner, ChemPlusChem, DOI: 10.1002/cplu.201200285.

[15] H. Karoui, F. Chalier, J. P. Finet, P. Tordo, Org. Biomol. Chem. 9 (2011) 2473-2480.

[16] V. A. Bolshov, A. V. Toktarev, A. M. Volodin, Mendeleev Commun. 4(6) (1994) 212-213.

[17] H. Garcia, H. D. Roth, Chem. Rev. 102 (2002) 3947-4007.

[18] B. R. Goodman, K. C. Hass, W. F. Schneider, J. B. Adams, Catal. Lett. 68 (2000) 85-93.

\section{Graphical Abstract}

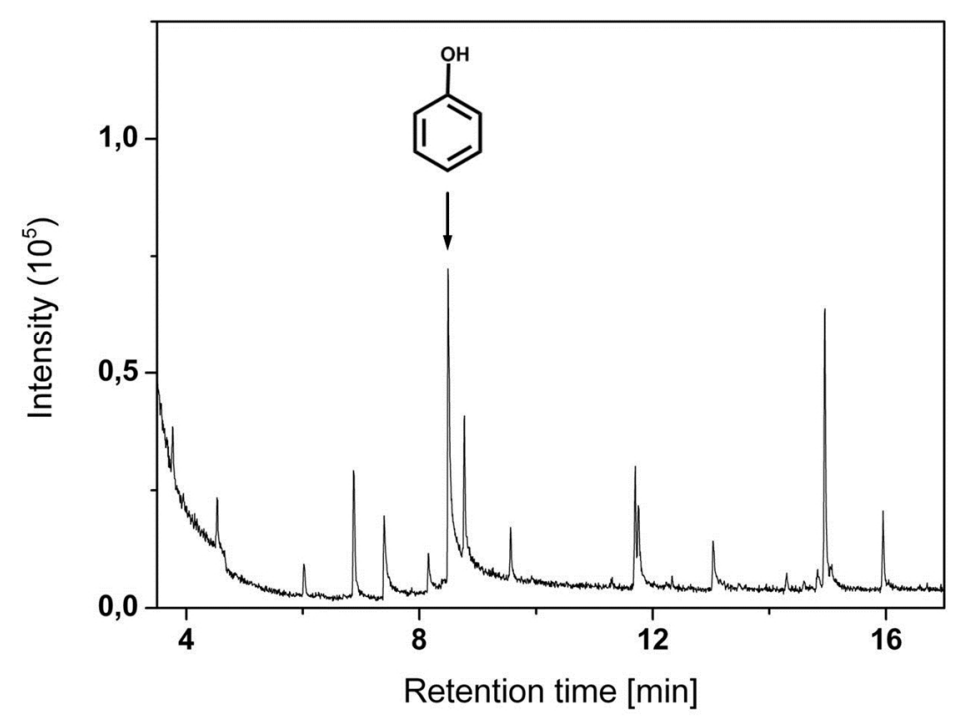

